\title{
The Contribution of Academic Behavioural Confidence, Self Esteem and Social Anxiety to College Student Career Decision Making Self Efficacy
}

\author{
Ruseno Arjanggi ${ }^{1}$, Hartono $^{2}$, Made Dwi Adnjani ${ }^{3}$, Hidayatus Sholihah ${ }^{4}$ \\ \{seno.ruseno@gmail.com ${ }^{1}$ \} \\ Universitas Islam Sultan Agung, Indonesia ${ }^{1,2,3,4}$
}

\begin{abstract}
The purpose of this study was to examine the effect of self-esteem, academic influence behavioural confidence and social anxiety on career decision making selfefficacy. Nine hundred thirty-five students completed the self-esteem, academic behavioural confidence, social anxiety and career decision making self-efficacy scales. The results of this study indicate that the fittest model capable of predicting career decision making self-efficacy is academic behavioural confidence. While the other two predictors, namely self-esteem and social anxiety when excluded from the analysis, further strengthen the influence of academic behavioural predictors on the formation of career decision self-efficacy.
\end{abstract}

Keyword: Career Decision-Making Self-Efficacy, Self-Esteem, Academic Behavioural Confidence, Social Anxiety.

\section{Introduction}

Career decision making is an essential skill that can be used throughout the life span, and career decision making is a skill that can be learned [1]. The stages in the career decisionmaking process are passed by identifying and processing information skills that are the basis for making decisions including career decision making [2][5]. Career decisions are a complex process, as a result, career counsellors are faced with various difficulties experienced by individuals when making career decisions [6].

Career decision self-efficacy is a career decision concept from the perspective of the social cognitive career theory perspective [7]. Social cognitive theory has a role in explaining the dynamics of various factors that influence career development both internally and externally through career self-efficacy [8]. Social cognitive career theory discovers various individual and distal contextual factors that contribute to one's learning experience that serves as a basis for developing self-efficacy and outcome expectations [7]. Self-efficacy and expectations of these results, in turn, lead to the interests, goals, and performance of individual career development [7].

Socioeconomic status and family support are related to career decision self-efficacy and outcome expectation [9]. The correlation between career obstacles and career decision selfefficacy is mediated by hopelessness, while the relationship between locus of control and career decision self-efficacy is fully mediated by hopelessness [10]. Individuals with feminine or masculine gender roles have higher career decision self-efficacy levels than those who have indeterminate gender roles, in addition, individuals with androgynous gender roles have career 
decision self-efficacy levels compared to those who have feminine and masculine gender roles, or indeterminate [11].

Chance events such as job fairs are known to be able to influence career decisions from $69.1 \%$ of the sample and locus of control is moderately related to chance events [12]. Selfefficacy of career decision making as an intervening variable of parental support and teacher support for career optimism in students, indicating the importance of the role of career decision making self-efficacy variable on students [4].

The adolescent is an unstable age so that there is considerable variation between at their initial career level and at the level of decision changes in the determination of the next career [3]. Developments in orientation related to environmental growth and self-exploration and the development of experiences in environmental exploration correlate with progress in commitment and career decision status [3][13]. The importance of career deciding at the beginning before entering college has a relationship with academic achievement during the first year in higher education [14].

The adolescent who has personality needs for professionals influence their alternative career choices or career development [15]. Identifying interests concerning personality types can achieve the implementation of a system of professional values or when someone revises career planning achieved in adulthood [15]. Career decision making in adulthood is different from the pattern of career decision making in adolescents who still tend to be unstable. Adult individuals increase the compatibility between professional requirements and professional interests by supporting and identifying alternative analyses during the decision-making process [15].

Different cultural backgrounds find to influence individual career decisions, which means that the more adaptive one's career decision making a profile, the smaller the difficulty in making decisions [5]. Cultural differences do not always have meaning in influencing adolescent career choices because adolescents have almost the same characteristics in some cultures [5]. Based on previous research, this study is interested in identifying factors that influence career decisions in adolescents. According to the researchers' knowledge, no similar research conducted in Indonesia.

The objectives of this study summarised in the following research questions:

a) Is there an interaction effect between academic behavioural confidence, self-esteem, and social anxiety on career decision making self-efficacy?

b) Are there gender differences in career decision making self-efficacy, academic behavioural confidence, self-esteem and social anxiety?

\section{Research Methods}

\subsection{Participants}

The participants of this study were 935 students from two private universities involved in this study, 309 male students (33\%) and 626 (67\%) female students. The participants of this study were drawn from 4 study programs namely psychology $415(44.4 \%)$ students, Communication Studies 127 (13.6\%) students, 57 English Education (6.1\%) students, Islamic Religious Education 336 (35.9\%) students. The ethnicity of the participants consisted of 912 students from Javanese ethnicity, 4 from Bugis, 5 from Sundanese, 3 from Malay, 2 students 
each from Buton and Chinese. Each other 1 student from Madura, Dayak, India, Minang, Tolaki, Serawi, and Batak.

\subsection{Measures}

\subsubsection{Career Decision Making Self Efficacy}

The Career Decision Making Self-Efficacy Scale (CDMSE) used in this study was arranged based on the behavioural domain that is relevant to the career decision making process that is included as a behaviour that shows five Career Award Competencies postulated in the career maturity model [16][17]. The domain of career maturity is behaviour that is relevant to career choice competencies, which include: (1) accurate self-assessment, (2) gathering job information, (3) choosing goals, (4) making plans for the future, and (5) completion problem. CDMSE has been one of the most widely studied constructs since the items were developed and introduced in the study Taylor \& Betz (1983) about developing the CDMSE scale. Previous studies using the same scale in the English version obtained internal consistency values above 0.9 [19]-[21] in the Chinese version also found internal consistency above 0.9 [22] in the Turkish version found internal consistency above 0.8 [23][24]. The CDMSE scale used in this study is a sort form consisting of 25 items that were adapted by double translate and expert panel to determine the appropriate items in the context of the study participants.

\subsubsection{Academic Behavioural Confidence}

Academic Behavioral Confidence scale used in this study has been developed and used previous research [25][26], which consists of 23 items with a choice of response 1 is not very suitable, up to 5 very suitable with my condition. Academic Behavioral Confidence scale in this study is translated by double expert translate which is then compared and overall translation until there are no significant differences, so it can be used immediately.

\subsubsection{Self-esteem}

Rosenberg's self-esteem scale develops by Rosenberg [27] consists of 10 items with a rating system of 5 Likert scaling models from very inappropriate to very appropriate. In previous studies, this scale had a convincing internal consistency of the item [28][30]. Rosenberg's self-esteem scale in this study was translated by double expert translate which was then compared and overall translation until there were no significant differences between translator.

\subsubsection{Social Anxiety}

The social anxiety scale used in this study is a translation of the social anxiety scale from La Greca [31]. The selection of the social anxiety scale measurement domain is based on previous studies that are suitable for college students [32][35], this scale consisting of 18 items with a choice of 1 is not very suitable for my condition up to 5 is very suitable for my condition. The social anxiety scale in this study was translated by double expert translate which was then compared and overall translation until there was no significant difference. 


\section{Results and Discussion}

The reliability coefficient uses Cronbach's alpha for all four scales. Alpha coefficients for all four scales are in the range 726-919 the overall coefficient is above 70, as the required criteria [36]. While the corrected item-total correlation career decision making self-efficacy scale is in the range 321-537, the self-esteem scale is in the range 322-569, the scale of academic behavioural confidence is in the range 346-599, and the social scale anxiety is in the range 417-725.

Table 1. Cronbach's alpha coefficient four scales

\begin{tabular}{lcc}
\hline \multicolumn{1}{c}{ Scales } & Range $\mathrm{r}_{\mathrm{ix}}$ & Alpha coefficients \\
\hline Career decision making self-efficacy & $.321-.537$ & .840 \\
Self-esteem & $.322-.569$ & .726 \\
Academic behavioural confidence & $.346-.599$ & .890 \\
Social anxiety & $.417-.725$ & .919 \\
\hline
\end{tabular}

Multiple regression analysis with the enter method is used to test the third predictor model in predicting the formation of dependent variables. Table 2 shows that the interaction of the three predictor variables is able to predict the formation of career decision making selfefficacy. However, among the three predictors seen from the partial correlation value and the significance value, it is known that the social anxiety variable does not significantly influence the career decision self-efficacy. The contribution of the three predictors in predicting the formation of career decision making self-efficacy is approximately $31.4 \%$.

Table 2. Multiple regression results of academic behavioural confidence, self-esteem, and social anxiety

\begin{tabular}{clrrrrr}
\hline Model & \multicolumn{1}{c}{$B$} & \multicolumn{1}{c}{ SE } & \multicolumn{1}{c}{$\beta$} & \multicolumn{1}{c}{$\mathrm{r}$} & \multicolumn{1}{c}{$\mathrm{R}^{2}$} \\
\hline \multirow{2}{*}{1} & Constant & 28.001 & 1.772 & & 15.797 & .314 \\
& Academic behavioural confidence & .351 & .023 & .451 & $15.436^{* *}$ & \\
& Self-esteem & .388 & .057 & .213 & $6.818^{* *}$ & \\
& Social anxiety & .003 & .019 & .004 & .143 & \\
\hline
\end{tabular}

$* * \mathrm{p}<.01$

Analysis of the data used in stepwise regression analysis with the aim to get the fittest model of the influence of three independent variables, namely academic behavioural confidence, self-esteem, social anxiety on career decision making self-efficacy.

Table 3. Stepwise multiple regression results of academic behavioural confidence and self-esteem

\begin{tabular}{|c|c|c|c|c|c|c|}
\hline Model & $B$ & & SE & $\beta$ & $\mathrm{t}$ & $\mathrm{R}^{2}$ \\
\hline \multirow[t]{2}{*}{1} & Constant & 31.948 & 1.356 & & $23.557 * *$ & .277 \\
\hline & Academic behavioural confidence & .411 & .022 & .527 & $18.870^{* *}$ & \\
\hline \multirow[t]{3}{*}{2} & Constant & 28.152 & 1.420 & & $19.827 * *$ & .315 \\
\hline & Academic behavioural confidence & .351 & .023 & .451 & $15.452 * *$ & \\
\hline & Self-esteem & .385 & .053 & .211 & $7.254 * *$ & \\
\hline
\end{tabular}

As shown in table 3 , academic behavioral confidence $(\beta=.447, p<.001$ and self-esteem $(\beta$ $=.213, \mathrm{p}<.001)$ significantly predicts career decision making self-efficacy. Approximately $31.3 \%$ of the total variation is explained by the two predictors, whereas the regression coefficient for social anxiety is shown to be insignificant $(\beta=.002, \mathrm{p}>.05)$ this finding shows that career decision self-efficacy is predicted by academic behavioural confidence and selfesteem. from the analysis because it weakens the formation of the dependent variable More or 
less the total variation is explained by $31.5 \%$ by two predictor variables namely academic behavioural confidence and self-esteem, while the one predictor model, academic behavioural confidence is able to explain the total variance of $27.7 \%$, the total increase in variation after adding self- Esteem as a predictor is $3.8 \%$ if seen from the R2 value in table 2 and table 3 model 2 it is known that the R2 value decreases with the inclusion of social anxiety variables, so in the stepwise predictor regression analysis social anxiety is excluded from the analysis.

Table 4. Stepwise multiple regression results of academic behavioural confidence and self-esteem for female

\begin{tabular}{|c|c|c|c|c|c|c|}
\hline Model & $B$ & & $\mathrm{SE}$ & $\mathrm{B}$ & $\mathrm{t}$ & $\mathrm{R}^{2}$ \\
\hline \multirow[t]{2}{*}{1} & Constant & 28.841 & 1.681 & & $17.155^{* *}$ & .310 \\
\hline & Academic behavioural confidence & .452 & .027 & .557 & $16.774 * *$ & \\
\hline \multirow[t]{3}{*}{2} & Constant & 25.836 & 1.709 & & $15.117 * *$ & .347 \\
\hline & Academic behavioural confidence & .385 & .028 & .475 & $13.530 * *$ & \\
\hline & Self-esteem & .371 & .061 & .212 & $6.048 * *$ & \\
\hline
\end{tabular}

Table 5. Stepwise multiple regression results of academic behavioural confidence

\begin{tabular}{clrrrrr}
\multicolumn{7}{c}{ and self-esteem for male } \\
\hline \multicolumn{1}{c}{$B$} & \multicolumn{1}{c}{ SE } & \multicolumn{1}{c}{ B } & \multicolumn{1}{c}{ t } & \multicolumn{1}{c}{$\mathrm{R}^{2}$} \\
\hline Model & & 36.201 & 2.267 & & $15.971^{* *}$ & .243 \\
& Constant & .360 & .036 & .495 & $19.872^{* *}$ & \\
\hline \multirow{2}{*}{2} & Academic behavioural confidence & 31.693 & 2.544 & & $12.457^{* *}$ & .272 \\
& Constant & .315 & .038 & .434 & $8.349^{* *}$ & \\
& Academic behavioural confidence & .370 & .102 & .189 & $3.638^{* *}$ & \\
\hline & Self-esteem & & & &
\end{tabular}

**<.01

This research aims to test the hypotheses of the influence of academic behavioural confidence, self-esteem, and social anxiety on career decision self-efficacy. This study found that the fittest model predicts career decision self-efficacy are academic behavioural confidence and self-esteem. Previous studies have not discussed the relationship between the three variables. Previous studies discuss many studies conducted in accordance with the results of this study [4][7][37].

Table 6. Gender differences in students' career decision making self-efficacy, academic behavioural

\begin{tabular}{|c|c|c|c|c|c|c|c|c|}
\hline \multirow[t]{2}{*}{ Variables } & \multicolumn{2}{|l|}{ All } & \multicolumn{2}{|c|}{ Male } & \multicolumn{2}{|c|}{ Female } & \multirow{2}{*}{$\mathrm{F}$} & \multirow[b]{2}{*}{$p$} \\
\hline & Mean & SD & Mean & SD & Mean & SD & & \\
\hline $\begin{array}{l}\text { Career } \\
\text { decision } \\
\text { making self- } \\
\text { efficacy }\end{array}$ & 57.2328 & 7.50661 & 58.2252 & 8.00927 & 56.7540 & 7.20956 & 7.883 & .005 \\
\hline $\begin{array}{l}\text { Academic } \\
\text { behavioural } \\
\text { confidence }\end{array}$ & 61.593 & 9.63710 & 61.2285 & 11.02598 & 61.7700 & 8.89412 & .643 & .423 \\
\hline Self-esteem & 19.3696 & 4.11829 & 19.5662 & 4.09609 & 19.2748 & 4.12887 & 1.020 & .313 \\
\hline $\begin{array}{l}\text { Social } \\
\text { anxiety }\end{array}$ & 32.2845 & 11.8382 & 30.6722 & 12.22526 & 33.0623 & 11.57671 & 8.370 & .004 \\
\hline
\end{tabular}

Table 6 shows the mean scores between male and female students. Male students had higher career decision self-efficacy scores than female students $(F=7.833, p<0.05)$. There 
was a difference in scores on variable social anxiety, female students' social anxiety scores were higher than male students $(\mathrm{F}=8,370, \mathrm{p}<0.05)$. There were no differences in mean scores in the academic behavioral confidence variables $(F=.643, p>0.05)$ and self-esteem $(F=$ $1.020, \mathrm{p}>0.05)$. Descriptive statistical analysis shows the mean score for the career decision making self-efficacy variable at $57.2328(\mathrm{SD}=7.50661)$, the mean score for the self-esteem variable at $19.3696(\mathrm{SD}=4.11829)$, the average score for the academic behavioral confidence variable at $61.593(\mathrm{SD}=9,63710))$ and the mean score for social anxiety variables was $32.3070(\mathrm{SD}=11.84170)$.

Data analysis to obtain answers to the first hypothesis was carried out separately between female and male genders. Based on the analysis of students found that both genders found the same results as the previous analysis, which eliminates social anxiety variables. The research finding proves that academic behavioural confidence and self-esteem are two variables are able to predict career decision self-efficacy.

The second hypothesis of this study is whether there are differences in career decision selfefficacy, academic behavioural confidence, self-esteem, and social anxiety in terms of gender differences. This study found that there were differences in career decision self-efficacy and social anxiety, but no differences found in the other two variables, namely academic behavioural confidence and self-esteem. Career decision self-efficacy for male students is higher than for female college students. Social anxiety also found differences between male and female students, female students were more anxious compared to other genders. The limitation of this study is the dominance of the female gender from this study, which reflects the unequal distribution of gender in research. Consequently, this study does not have a balanced gender perspective.

\section{Conclusion}

This study examines the influence of three predictors namely academic behavioral confidence, self-esteem, and social anxiety on career decision making self-efficacy. This study found that two predictors have an influence on career decision making self-efficacy, namely academic behavioral confidence and self-esteem.

The findings of this study have the implication that to improve self-efficacy in career decisions students need to have an understanding of themselves and beliefs about their potential through the search for interests and talents during university studies or obtained at an earlier stage. A meaningful educational process for students to carry out role experiments such as work internships and career counselling will help in the restructuring process of career decisions that have taken.

Females are lower in career decision making self-efficacy and higher in social anxiety can be tested for causes with other variables not examined in this study that theoretically affect both variables such as conformity, social support and other variables. The limitation of this study is the need for multi-level analysis to determine whether group contexts contribute to the influence of predictors on dependent variables given the sample of this study from two different institutions and departments. So it is possible for differences in context during the study process such as the burden of work in the laboratory, individual tasks, group assignments, and course characteristics. 


\subsection{Acknowledgement}

This work supported by the Ministry of Research, Technology, and Higher Education Research Grant 2018-2019.

\section{References}

[1] L. Sovet, J. Tak, and S. Jung, "Validation of the career decision-making difficulties questionnaire among Korean college students," J. Career Assess., vol. 23, no. 4, pp. 661-676, 2015.

[2] T. L. Walker and T. J. G. Tracey, "The role of future time perspective in career decisionmaking," J. Vocat. Behav., vol. 81, no. 2, pp. 150-158, 2012.

[3] F. Bacanli, "Career decision-making difficulties of Turkish adolescents," Int. J. Educ. Vocat. Guid., vol. 16, no. 2, pp. 233-250, 2016.

[4] P. R. J. M. Garcia, S. L. D. Restubog, P. Bordia, S. Bordia, and R. E. O. Roxas, "Career optimism: The roles of contextual support and career decision-making self-efficacy," J. Vocat. Behav., vol. 88, pp. 10-18, 2015.

[5] T. Willner, I. Gati, and Y. Guan, "Career decision-making profiles and career decision-making difficulties: A cross-cultural comparison among US, Israeli, and Chinese samples," J. Vocat. Behav., vol. 88, pp. 143-153, 2015.

[6] R. Arjanggi, "Identifikasi permasalahan Pengambilan keputusan karir remaja," Psikologika, vol. 22, no. 1, pp. 151-157, 2017.

[7] B. Y. Choi, H. Park, E. Yang, S. K. Lee, Y. Lee, and S. M. Lee, "Understanding career decision self-efficacy: A meta-analytic approach,” J. Career Dev., vol. 39, no. 5, pp. 443-460, 2012.

[8] A. Bandura, Self-efficacy in Changing Societies. New York: United States of America by Cambridge University Press, 1997.

[9] J. Metheny and E. H. Mcwhirter, "Contributions of social status and family support to college students' career decision self-efficacy and outcome expectations," J. Career Assess., vol. 21, no. 3, pp. 378-394, 2013.

[10] O. Ulas and I. Yildirim, "Influence of locus of control, perceived career barriers, negative affect, and hopelessness on career decision-making self-efficacy among Turkish university students," Int. J. Educ. Vocat. Guid., vol. 19, no. 1, pp. 85-109, 2019.

[11] N. Bolat and H. Odac, "High School Final Year Students ' Career Decision-Making SelfEfficacy, Attachment Styles and Gender Role Orientations," Curr. Psychol., vol. 37, no. 2, pp. 254-259, 2016.

[12] J. E. H. Bright, R. G. L. Pryor, and L. Harpham, "The role of chance events in career decision making," J. Vocat. Behav., vol. 66, no. 3, pp. 561-576, 2005.

[13] V. Germeijs and K. Verschueren, "High school students' career decision-making process: A longitudinal study of one choice," J. Vocat. Behav., vol. 68, no. 2, pp. 189-204, 2006.

[14] V. Germeijs and K. Verschueren, "High school students' career decision-making process: Consequences for choice implementation in higher education," J. Vocat. Behav., vol. 70, no. 2, pp. 223-241, 2007.

[15] M. Guranda, "The Importance of Adult's Personality Traits and Professional Interests in Career Decision Making," Procedia - Soc. Behav. Sci., vol. 136, pp. 522-526, 2014.

[16] J. O. Crites, "A model for the measurement of vocational maturity.," J. Couns. Psychol., vol. 8, no. 3 , p. 255,1961 .

[17] J. O. Crites, "Measurement of vocational maturity in adolescence: I. Attitude test of the Vocational Development Inventory.," Psychol. Monogr. Gen. Appl., vol. 79, no. 2, p. 1, 1965.

[18] K. M. Taylor and N. E. Betz, "Applications of self-efficacy theory to the understanding and treatment of career indecision," J. Vocat. Behav., vol. 22, no. 1, pp. 63-81, 1983.

[19] E. Bullock-Yowell, L. Andrews, and M. E. Buzzetta, "Explaining career decision-making selfefficacy: Personality, cognitions, and cultural mistrust," Career Dev. Q., vol. 59, no. 5, pp. 400- 
$411,2011$.

[20] G. N. Burns, D. Jasinski, S. Dunn, and D. Fletcher, "Academic support services and career decision-making self-efficacy in student athletes," Career Dev. Q., vol. 61, no. 2, pp. 161-167, 2013.

[21] S. L. Peterson and R. C. Delmas, "The component structure of career decision-making selfefficacy for underprepared college students," J. Career Dev., vol. 24, no. 3, pp. 209-225, 1998.

[22] Z. Jiang, "Core self-evaluation and career decision self-efficacy: A mediation model of value orientations," Pers. Individ. Dif., vol. 86, pp. 450-454, 2015.

[23] A. Buyukgoze-Kavas, "A psychometric evaluation of the career decision self-efficacy scaleshort form with Turkish university students," J. Career Assess., vol. 22, no. 2, pp. 386-397, 2014.

[24] E. Işık, "Effects of a brief interest inventory intervention on career decision self-efficacy," $J$. Psychol. Couns. Sch., vol. 24, no. 2, pp. 215-226, 2014.

[25] P. Sander and L. Sanders, "Measuring academic behavioural confidence: the ABC scale revisited," Stud. High. Educ., vol. 34, no. 1, pp. 19-35, 2009.

[26] P. Sander, J. De La Fuente Arias, K. Stevenson, and T. Jones, "A validation of the academic behavioural confidence scale with spanish psychology students," Psychol. Learn. Teach., vol. 10, no. 1, pp. 11-24, 2011.

[27] M. Rosenberg, Society and the adolescent self-image. Princeton, NJ: Princeton University Press, 1965.

[28] S. M. Aldaqal and M. G. Sehlo, "Self-esteem and quality of life in adolescents with extreme obesity in Saudi Arabia: the effect of weight loss after laparoscopic sleeve gastrectomy," Gen. Hosp. Psychiatry, vol. 35, no. 3, pp. 259-264, 2013.

[29] J. E. Aspelmeier, M. M. Love, L. A. Mcgill, A. N. Elliott, and T. W. Pierce, "Self-esteem, locus of control, college adjustment, and GPA among first- and continuing-generation student: a moderatior model of generational status," Res. High. Educ., vol. 53, pp. 755-781, 2012.

[30] J. Zhao, F. Kong, and Y. Wang, "The role of social support and self-esteem in the relationship between shyness and loneliness," Pers. Individ. Dif., vol. 54, no. 5, pp. 577-581, 2013.

[31] A. M. La Greca and N. Lopez, "Social Anxiety Amon Adolescents: Linkages with Peer Relation s and Friendships," J. Abnorm. Child Psychol., vol. 26, no. 2, pp. 83-94, 1998.

[32] M. Puklek and G. Vidmar, "Social anxiety in Slovene adolescents: Psychometric properties of a new measure, age differences and relations with self-consciousness and perceived incompetence," Eur. Rev. Appl. Psychol., vol. 50, no. 2, pp. 249-258, 2000.

[33] A. H. Nordstrom, L. M. S. Goguen, and M. Hiester, "The Effect of Social Anxiety and SelfEsteem on College Adjustment, Academics, and Retention,” J. Coll. Couns., vol. 17, no. April, pp. 48-64, 2014.

[34] K. Ranta, N. Junttila, E. Laakkonen, A. Uhmavaara, and A. M. La Greca, "Social Anxiety Scale for Adolescents ( SAS-A ): Measuring social anxiety among Finnish adolescent," Child Psychiatry Hum. Dev., vol. 43, no. February, pp. 574-591, 2012.

[35] L. J. Garcia-Lopez, C. J. Ingles, J. M. Garcia-Fernandez, M. D. Hidalgo, R. Bermejo, and M. P. Levpuscek, "Psychometric Properties and Clinical Cut-Off Scores of the spanish version of the social anxiety scale for adolescents," Jounal Personal. Assess., vol. 93, no. 5, pp. 474-482, 2011.

[36] R. A. Peterson, "Meta-analysis of Alpha Cronbach's Coefficient," J. Consum. Res., vol. 21, no. 2, pp. 381-391, 2013.

[37] R. Chiesa, F. Massei, and D. Guglielmi, "Career Decision-Making Self-Efficacy Change in Italian High School Students Boosting Career Exploration :," J. Couns. Dev., vol. 94, no. April, pp. 210-225, 2016. 